\title{
Mating frequency of ant queens with alternative dispersal strategies, as revealed by microsatellite analysis of sperm
}

\author{
MICHEL CHAPUISAT \\ Museum of Zoology, CP 448, CH-1000 Lausanne 17, Switzerland, and Institute of Zoology and Animal Ecology, University of \\ Lausanne, CH-1015 Lausanne, Switzerland
}

\begin{abstract}
In social Hymenoptera (ants, bees, and wasps), the number of males that mate with the same queen affects social and genetic organization of the colony. However, the selective forces leading to single mating in certain conditions and multiple mating in others remain enigmatic. In this study, I investigated whether queens of the wood ant Formica paralugubris adopting different dispersal strategies varied in their mating frequency (the number of males with whom they mated). The frequency of multiple mating was determined by using microsatellite markers to genotype the sperm stored in the spermatheca of queens, and the validity of this method was confirmed by analysing mother-offspring combinations obtained from experimental single-queen colonies. Dispersing queens, which may found new colonies, did not mate with more males than queens that stayed within polygynous colonies, where the presence of numerous reproductive individuals ensured a high level of genetic diversity. Hence, this study provides no support to the hypotheses that multiple mating is beneficial because it increases genetic variability within colonies. Most of the F. paralugubris queens mated with a single male, whatever their dispersal strategy and life history. Moreover, multiple mating had little effect on colony genetic structure: the effective mating frequency was 1.11 when calculated from within-brood relatedness, and 1.13 when calculated from the number of mates detected in the sperm. Hence, occasional multiple mating by F. paralugubris queens may have no adaptive significance.
\end{abstract}

Keywords: dispersal, Formica paralugubris, mating frequency, microsatellites, polyandry, social insects

Received 20 October 1997; revision received 15 January 1998; accepted 19 February 1998

\section{Introduction}

Queen mating frequency varies both within and among species of social Hymenoptera (for reviews, see Page 1986; Keller \& Reeve 1994; Boomsma \& Ratnieks 1996). Understanding the causes of this variation is of interest, because mating frequency affects colony genetic structure, which has important consequences for social evolution (Hamilton 1964b; Trivers \& Hare 1976; Starr 1984). However, despite a considerable amount of theoretical research, the actual selective factors promoting single mating in certain conditions and multiple mating in others remain enigmatic (Crozier \& Page 1985; Page 1986; Bourke \& Franks 1995; Boomsma \& Ratnieks 1996; Crozier \& Pamilo 1996).

Correspondence: Present address: School of Genetics, La Trobe University, Bundoora, Victoria 3083 Australia. Fax: +61 39479 2480; E-mail: michel@gen.latrobe.edu.au
Mating with more than one male will probably entail some cost to the queen. Hypothetical costs include time loss, energy loss, and increased predation and parasite transmission risks (Thornhill \& Alcock 1983; Sherman et al. 1988). Moreover, multiple paternity tends to decrease relatedness among offspring, which might hinder the evolution or the maintenance of worker behaviour by kin selection in species without morphological castes (Hamilton 1964a,b; Pamilo 1991b). Finally, mating with multiple males enhances the probability that the queen will produce some diploid males, which entails a cost under certain life-history scenarios (Crozier \& Page 1985; Pamilo 1991a; Pamilo et al. 1994). For example, the load imposed by the production of diploid males jeopardizes the survival of incipient colonies in some populations of monogynous (i.e. with a single queen per nest) fire ants (Ross \& Fletcher 1986).

In contrast, various potential benefits of multiple mating have been proposed (for reviews, see Crozier \& Page 
1985; Page 1986; Keller \& Reeve 1994). A first group of hypotheses rely on increased genetic variability within colonies, and have been collectively referred to as the GV hypotheses (Keller \& Reeve 1994). These hypotheses propose that queens in colonies where the genetic variability is higher have a selective advantage, for one of the following reasons. Their colonies may: (i) have a more complete and efficient expression of castes or behaviours (Crozier \& Page 1985); (ii) tolerate a greater range of environmental conditions (Crozier \& Page 1985); (iii) better resist parasites or pathogens (Hamilton 1987; Sherman et al. 1988; Shykoff \& Schmid-Hempel 1991a,b; SchmidHempel 1994; but see Boomsma \& Ratnieks 1996); (iv) be less affected by the load of diploid males, if life-history conditions are such that colony growth and survival increase when the variance in diploid male production decreases (Page 1980; Page \& Metcalf 1982; Crozier \& Page 1985; Ratnieks 1990; Pamilo et al. 1994), for example, multiple mating might be selected for in monogynous colonies reproducing by fission during the asymptotic phase of colony growth (Crozier \& Page 1985; Pamilo et al. 1994); or (v) specialize in male production, which would be in the interest of both workers and queens (Moritz 1985; Queller 1993b; Ratnieks \& Boomsma 1995).

Multiple mating may also be advantageous for reasons independent from an increased genetic variability within colonies. Further hypotheses propose that queens mate multiply: (vi) to increase the life-time supply of sperm, because queens do not remate subsequently (Cole 1983); (vii) to limit the risk of mating with only sterile males (e.g. Walker 1980); (viii) to increase sperm competition and select the most competitive sperm to fertilize their eggs (Keller \& Reeve 1995); or (ix) because it would be more costly to resist male sexual attempts than to mate (e.g. Thornhill \& Alcock 1983; CluttonBrock \& Parker 1995).

To date, there is little empirical evidence for most of the hypothetical costs and benefits listed above. The GV hypotheses predict a negative association between polyandry and polygny (the presence of multiple reproductive queens), under the assumption that mating incurs costs (Keller \& Reeve 1994). This is because the presence of multiple queens ensures a high amount of intracolony genetic variability, which render multiple mating superfluous. In support of this hypothesis, Keller \& Reeve (1994) found a negative correlation between mating frequency and queen number across 19 genera of ants. However, the mating frequency data used in this analysis had been obtained by various methods, and were not always very reliable (Keller \& Reeve 1994; Boomsma \& Ratnieks 1996). When using only accurate paternity frequency data from 34 species of ants, Boomsma \& Ratnieks (1996) did not detect such a correlation. Hence, the effective importance of the GV hypotheses in the evolution of polyandry remains elusive.

A better understanding of the factors influencing mating frequency evolution requires detailed comparative studies, both within and across species. In this study, I examined whether queens of the wood ant Formica paralugubris with alternative dispersal strategies differ in their mating frequency.

Queens of the study population, in the Swiss Jura mountains, show two distinct dispersal and mating behaviours (Cherix et al. 1991). They can mate and stay within or close to their natal nest, or disperse on the wing and mate in distant meadows (Cherix et al. 1991, 1993).

Detailed genetic studies with microsatellite markers revealed that most queens present in old nests were mated and had remained locally (Chapuisat et al. 1997; Chapuisat 1997). Mature nests contain many reproductive queens, which results in high intranest genetic diversity and low relatedness among workers (Pamilo et al. 1992; Chapuisat et al. 1997). However, despite a high number of reproductive individuals, distant nests are significantly differentiated, which indicates that long-distance gene flow between established nests is very limited (Chapuisat et al. 1997). Three different models and two independent data sets were used to estimate the proportion of reproductive individuals that were recruited from within their natal nest, consistently yielding values between 99.5\% and 99.8\% (Chapuisat et al. 1997; Chapuisat 1997). The proportion of local recruitment was estimated to be at least $95 \%$, based on calculations using measures of genetic differentiation equal to the lowest limit of the $95 \%$ confidence interval and effective number of queens conservatively estimated to equal 100 (Chapuisat et al. 1997; Chapuisat 1997). Hence, these data demonstrate that the vast majority of the reproductive queens present in old nests were mated and had stayed within or close to their natal nest.

In contrast, many new queens and males leave their nest and fly to open meadows hundreds of metres away, where they mate (Cherix et al. 1991, 1993). After mating, queens disperse further. They can either seek adoption in existing nests of the same species, or attempt to found new colonies by parasitizing the nests of Serviformica ants (Kutter 1977). In this latter case, the intruder queen kills the resident queen, and the first generation of the intruder's offspring are reared by the heterospecific workers. Subsequently, the newly founded Formica colony grows slowly. Several generations of workers are reared before new males and queens are produced (Gösswald 1953, 1989).

Queens staying within polygynous nests and queens dispersing to found new colonies face drastically different conditions. Therefore, the potential costs and benefits of multiple mating probably differ between these two groups of queens (Table 1).

On the one hand, overall costs of additional mating are expected to be smaller when mating occurs within the 


\begin{tabular}{|c|c|c|}
\hline \multirow[b]{2}{*}{ Factor } & \multicolumn{2}{|c|}{ Relative importance for: } \\
\hline & $\begin{array}{l}\text { Nondispersing } \\
\text { queens }\end{array}$ & $\begin{array}{l}\text { Dispersing } \\
\text { queens }\end{array}$ \\
\hline \multicolumn{3}{|l|}{$\underline{\text { Costs }}$} \\
\hline Time lost & Low & Low \\
\hline Energy lost & Low & Low \\
\hline Predation risk & None & Medium \\
\hline Parasite transmission risk & Low? & Medium? \\
\hline Higher probability to produce some diploid males & Low & High \\
\hline \multicolumn{3}{|l|}{ Benefits } \\
\hline \multicolumn{3}{|l|}{ Genetic variability hypotheses: } \\
\hline Better expression of castes or behaviours & None & High \\
\hline Increased range of environmental conditions & None & High \\
\hline Defence against parasites or pathogens & None & High \\
\hline Lower probability to produce many diploid males & Low & Low? \\
\hline Male-biased sex ratio & Low & High \\
\hline \multicolumn{3}{|l|}{ Other hypotheses: } \\
\hline Life-time supply of sperm & Low & High \\
\hline Bet-hedging against sterile males & Low & High \\
\hline Sexually selected sperm & Low? & Low? \\
\hline Cheaper than to resist & Medium? & Medium? \\
\hline
\end{tabular}

Table 1 Hypothetical costs and benefits of multiple mating by queens, and their relative importance for nondispersing queens (staying in polygynous nests) and for dispersing queens (which might found new colonies). Question marks indicate factors which are difficult to evaluate. Note that this is a list of possible factors. When compared to each other, factors certainly vary in both importance and applicability, and some may have no actual effect in the study species nest than when it occurs during dispersal flight (Table 1). Dispersing queens face a higher risk of predation, and may be more exposed to parasite transmission. Moreover, and perhaps more importantly, additional mating increases the probability that part of the diploid brood will develop into sterile males, which may entail a large cost to dispersing queens if a small load of diploid males greatly reduces the success of incipient colonies.

On the other hand, almost all the supposed benefits of multiple mating are likely to be higher for queens founding new colonies than for queens staying within polygynous colonies (Table 1). In particular, the GV hypotheses predict that the benefits of multiple mating should be larger for dispersing queens. This is because the relative effect of multiple mating on intranest genetic variability is much higher for dispersing queens founding new colonies than for queens staying within polygynous colonies, where the presence of numerous reproductive individuals already ensures a high genetic diversity (Keller \& Reeve 1994). Additionally, a larger supply of sperm and insurance against male sterility may also be more important for queens founding new colonies than for queens that can rely on nestmates to provide diploid individuals.

Hence, the comparison of mating frequency of queens with alternative dispersal strategies might help to understand which are the most important factors determining queen mating frequency. If dispersing queens show a mating frequency similar to or lower than that of queens remaining within polygynous nests, it would suggest that the costs of additional matings overcome the benefits of genetic variation or larger sperm stores. In contrast, a higher mating frequency of dispersing queens would support the various hypotheses proposing that multiple mating is particularly beneficial to solitary queens (Table 1).

In social Hymenoptera, queen mating frequencies have been traditionally estimated from observation of copulations, sperm counts of males and females, and analysis of mother-offspring combinations with genetic markers (see Boomsma \& Ratnieks 1996 for a critical review of the data and methods). The analysis of mother-offspring combinations is the most accurate method to measure the genetic consequences of mating behaviour, provided that large broods and sufficiently polymorphic markers are used. However, obtaining and analysing large broods from single queens often requires a considerable amount of work. Moreover, some polygynous species are difficult to rear in single-queen laboratory colonies, such that the progeny of single females cannot be separated (Queller 1993a). These problems can be avoided by using microsatellite markers to analyse the sperm stored in the spermatheca of queens (Evans 1993; Peters et al. 1995; Goodnight et al. 1996). The sperm-typing approach was chosen to investigate the frequency of multiple mating among F. paralugubris queens with alternative dispersal strategies. The reliability of the method was confirmed by comparing results from sperm typing and from mother-offspring analyses. 


\section{Materials and methods}

Sampling

Nondispersing queens were collected from 20 large polygynous nests located near the Chalet à Roch, in the Swiss Jura Mountains. Detailed microsatellite analyses revealed that about $99.5 \%$ of these queens had not dispersed, but rather had mated within the nest or close to it (Chapuisat et al. 1997; Chapuisat 1997).

Dispersing queens and males from the same population fly to open meadows, where they mate on the grass (Cherix et al. 1991). After having mated with one or several males, most queens fly away from the mating aggregation, ascending high in the sky, so that it is unlikely that they will mate again. Queens were captured with a net when they flew off the grass, at the mating place located in front of the Chalet à Roch. Note that dispersing queens and nondispersing queens belong to different cohorts.

\section{Microsatellite analysis of sperm and queens}

Queens were dissected in $10 \% \mathrm{NaCl}$ solution under a binocular microscope. Each spermatheca was placed in distilled water. If the spermatheca contained sperm, it was punctured with a pin, and about $15 \mu \mathrm{L}$ of sperm fluid was drawn out of the spermatheca with a pipette. Two methods were used to extract DNA from sperm fluid. First, sperm was incubated for $1 \mathrm{~h}$ at $37^{\circ} \mathrm{C}$ in a final concentration of $0.05 \mathrm{mg} / \mathrm{mL}$ proteinase $\mathrm{K}, 1.75 \mu \mathrm{M}$ SDS and $20 \mathrm{~mm}$ DTT, in order to lyse sperm cells (Gyllensten 1990). Proteinase $\mathrm{K}$ was then inactivated by heating the lysate for $10 \mathrm{~min}$ at $95^{\circ} \mathrm{C}$, and $1 \mu \mathrm{L}$ of this solution was used in Polymerase Chain Reactions (PCR). Alternatively, sperm extract was lysed by standard SDS/proteinase K digestion followed by phenol-chloroform extraction and ethanol precipitation (Sambrook et al. 1989). Pelleted DNA was resuspended in $100 \mu \mathrm{L}$ of distilled water, of which $1 \mu \mathrm{L}$ was used in PCR. Both methods of sperm extraction gave equally good results. Sperm extracts and queens were analysed at four microsatellite loci, following methods and primers given in Chapuisat (1996).

\section{Reliability of the sperm-typing method}

Because fertile males of Hymenoptera are haploid, the maximum number of alleles detected at any locus in the whole sperm stored by females provides a minimum estimate of the number of males that mated with the queen. Hence, this method can be used to detect the frequency of multiple mating in species where some queens mate singly and other multiply. However, the detection of multiple mating may be affected by contamination with queen DNA, by nondetection of multiple mates because they have identical genotypes, and by nondetection of the male that contributed fewer sperm due to nonamplification of the rarer DNA haplotype. The potential importance of these biases will be estimated for the simplest case where queens mate either once or twice, which is a common situation in Hymenoptera (Boomsma \& Ratnieks 1996). Additional simplifying assumptions are that the population is at Hardy-Weinberg equilibrium, that queens and males are unrelated, and that the loci are unlinked.

Contamination of the sperm with queen DNA during dissection results in scoring all the queen alleles from the sperm sample, at all loci. In the absence of contamination, such a pattern would appear when double mating occurs and the two males have the same alleles as the queen. The probability of this event can be calculated from the queen genotype (e.g. Avise 1994). It is the product over all loci of $2 p q$ at loci where the queen is heterozygous and $p^{2}$ at loci where the queen is homozygous ( $p$ and $q$ standing for the population frequencies of the alleles present in the queen at a given locus). When several moderately polymorphic microsatellite loci are used, this probability becomes very small, and therefore instances where all the queen alleles appear in the typing of the sperm can be reliably attributed to contamination.

Part of the double matings may remain undetected because the two males have identical genotypes. The probability that two random males share the same genotype is given by $\prod_{l} \sum_{i} p_{i}^{2}$, where $p_{i}$ stands for the population frequency of the $i$ allele at the $l$ locus (e.g. Boomsma \& Ratnieks 1996). Again, this probability becomes insignificant when several moderately polymorphic markers are used.

Cases of double mating will also escape detection if the DNA of one male is not amplified. This is more likely to occur when one of the males contributed only a small fraction of the sperm stored by the queen, because PCR is both a competitive and an exponential process, and thus is potentially difficult to control when several DNA targets are coamplified (e.g. Ferré et al. 1994). The sensitivity of the sperm-typing method was tested by mixing serial dilutions of sperm DNA from males of known genotypes that had been extracted from singly mated queens. Three combinations of sperm DNA extracted from six different males were analysed.

A further test of the validity of the sperm-typing method was conducted by establishing laboratory colonies with a single queen, and by analysing both mother-offspring combinations and sperm extracted from the queen spermatheca. Queens were reared in artificial nests made from two ceramic flower pots (Pamilo 1982, 1993; Chapuisat 1997). After 1 month, mother queens, larvae and pupae were collected and kept frozen for subsequent analyses. For 10 queens, microsatellite data were obtained for the queen herself, the sperm stored 
in her spermatheca and eight to 20 of her worker offspring. In five additional cases, both queen and 10 worker offspring were genotyped, but sperm could not be obtained because the queens had dried out in the freezer before dissection.

\section{Statistical analyses}

A potential difference in the frequency of multiple mating between dispersing and nondispersing queens was evaluated with $G$-test of independence, which is appropriate for two-way tables where the marginal totals have not been fixed (Sokal \& Rohlf 1995; p. 729). A power analysis was conducted to estimate the probability that a given deviation from the null hypothesis of no association between mating frequency and dispersal strategy would have been detected (Cohen 1988; p. 215). Power was calculated from the tables provided for the $\chi^{2}$-test, using a probability of type I error equal to 0.05 , and an effect size index $W$ equal to 0.3 , which is a conventional value for a medium degree of association (Cohen 1988; p. 227). Deviations from the null hypothesis that would correspond to $W=0.3$ were estimated by generating sets of hypothetical mating frequencies for dispersing and nondispersing queens, and then calculating $W$ (Cohen 1988; p. 224).

\section{Effective mating frequency}

Direct typing of the sperm contained in the spermatheca cannot provide an accurate estimate of the effective mating frequency, because the relative contribution of each mate cannot be determined by this method (see Starr 1984; Page 1986). However, a raw estimate of the effective mating frequency can be obtained if one assumes that each mate contributes equally to the brood. Under this assumption, the effective mating frequency is given by the harmonic mean of the number of mates per queen over all queens in the sample (e.g. Pamilo 1993; Queller 1993a; Ross 1993). This will be an overestimate of the actual paternity frequency in the population, because deviation from equal contribution of males tends to reduce the effective mating frequency (Starr 1984; Page 1986).

A more accurate estimate of the effective mating frequency $m_{e}$ can be obtained from the mean relatedness within broods of single queens $r_{b}$ by using the following formula:

$m_{e}=\frac{2}{4 r_{b}-1}$

(e.g. Pamilo 1993). The mean relatedness within broods was estimated with the method of Queller \& Goodnight (1989). Genotypes of 443 workers from 48 nests located in the same study population were used to determine the allele frequencies in the background population (Chapuisat et al. 1997; Chapuisat 1997). Groups were weighted equally, and the standard error was obtained by jackknifing over groups.

\section{Results}

Reliability of the sperm-typing method

Sperm were analysed from 166 queens. In five cases (3\% of all the queens analysed), none of the four microsatellite loci could be scored. The most probable explanation for these rare cases of nonamplification is that DNA was lost during the extraction procedure.

In five other cases, all the alleles present in the queen appeared in the typing of the sperm. The probabilities that these cases were due to genuine double mating were between 0.00002 and 0.001 , depending on queen genotype (mean 0.0005). Hence, these data probably resulted from contamination of the sperm extract with queen DNA, possibly in association with an absence or rarity of male DNA. These data were discarded from further analysis.

The probability that two random males had identical genotypes, calculated from allele frequencies in the local population, was 0.007 . This means that less than $1 \%$ of double matings would remain undetected due to identical paternal genotypes. The probabilities calculated above might tend to underestimate actual nondetection errors, because the population deviates from Hardy-Weinberg equilibrium (Chapuisat 1997; Chapuisat et al. 1997), and individuals mating within nests are moderately related (Chapuisat 1997). However, even if these probabilities are somewhat underestimated, the important point is that most cases of contamination can be reliably detected, and that the proportion of the double matings where the two males had identical genotypes was small.

Serial dilutions and mixing of sperm DNA from males of known genotype revealed that the rarest sperm haplotype was unambiguously detected until a ratio as low as 1:10. The detection threshold varied somewhat depending on the locus and the size of the allele under consideration. Similar results have been obtained with a single microsatellite in the ant Atta colombica (Gertsch \& Fjerdingstdad 1997).

Mating frequencies determined by mother-offspring analysis and by sperm typing were very similar (Table 2). In six cases out of 10, only one mate was detected in both mother-offspring and sperm analysis. Moreover, all the paternal alleles present in the offspring were detected in the sperm. Similarly, one case of double mating was detected both in sperm and offspring, and all paternal alleles were detected in the sperm. In a further case, one out of 20 offspring was sired by a second male, and the 


\begin{tabular}{|c|c|c|c|}
\hline \multirow{2}{*}{$\begin{array}{l}\text { No. of } \\
\text { queens }\end{array}$} & \multicolumn{2}{|c|}{ Mating frequency from: } & \multirow[b]{2}{*}{ Remark } \\
\hline & Mother-offspring* & Sperm & \\
\hline 6 & $1(10)$ & 1 & Methods give compatible results \\
\hline 1 & $2(9,1)$ & 2 & Methods give compatible results \\
\hline 1 & $2(19,1)$ & 1 & Rarer father not detected in sperm \\
\hline 1 & $3(4,3,1)$ & 3 & Methods give compatible resultst \\
\hline 1 & $1(10)$ & $? \ddagger$ & Contamination of sperm with queen DNA \\
\hline
\end{tabular}

Table 2 Queen mating frequency inferred from mother-offspring combinations and from microsatellite typing of the sperm stored in the spermatheca

${ }^{*}$ Number of offspring from each male given in parentheses.

tOne paternal allele not detected in sperm (see text).

$\ddagger$ The genotype from the sperm was identical to the queen genotype (see text).

alleles of this father were not detected in the sperm. This suggests that male haplotypes present at a low frequency in the sperm sometimes escape detection, as was suggested by the sperm DNA dilution and mixing experiment. One case of triple mating was detected both in offspring and sperm. All paternal alleles were detected at three loci in the sperm, and two out of three paternal alleles were detected at the fourth locus, which indicates that the sensitivity varies among loci and alleles. Finally, in one case, the alleles amplified from the sperm perfectly matched the queen genotype, at all four loci. As discussed above, this pattern is very unlikely to represent a real case of double mating $(P=0.0003)$, and is most probably due to contamination by queen DNA. The genotypes of the offspring were compatible with a single father having one of the queen alleles at each locus, a case which can occur by chance at a non-negligible frequency $(P=0.07)$. Overall, the comparison of mother-offspring and sperm-typing results suggests that both methods give comparable results in populations where queens mate with one to three males.

In the five additional combinations of queen and 10 offspring, for which no sperm analysis was conducted, only one father was detected. This further confirms that a large proportion of queens mate singly, and that the low mating frequency detected by sperm typing is not due to amplification problems.

\section{Comparison of mating frequency of dispersing and nondispersing queens}

Queen mating frequency through sperm typing was determined for 96 queens coming from polygynous nests and 59 dispersing queens. Overall, single-mating was detected for $78 \%$ of the queens, double-mating for $19 \%$, and triple-mating for 3\% (Table 3). The frequency of multiply mated queens was not significantly different between nondispersing queens collected from polygynous nests and dispersing queens (Table 3; $G=0.0005$, d.f. $=1, P=0.98$, power 0.96 ). For both groups of queens, multiple mating was detected for $22 \%$ of the queens.
Power analysis indicated that an effect size index of 0.3 would have been detected with a probability of 0.96 . This effect size index corresponds to the hypothetical case where $50 \%$ of the dispersing queens mate multiply, instead of the $22 \%$ observed. In the opposite direction, such an effect size corresponds to the case where $3 \%$ of nondispersing queens mate multiply, instead of $22 \%$. An effect size index of 0.3 is also obtained if, for example, $11 \%$ of the queens within nests and $35 \%$ of the dispersing queens would have mated multiply. Hence, differences of $20-30 \%$ in the proportion of single-mated queens would have been detected with high probability in this analysis.

\section{Effective mating frequency}

The effective mating frequency, estimated from the number of mates detected in the sperm (Table 3) with the assumption that each male contributes equally to the brood, was 1.13. The mean relatedness within 15 broods from single queens was $0.70 \pm 0.04$ (mean \pm SE). Hence, the effective mating frequency derived from within-brood relatedness was 1.11.

\section{Discussion}

Direct microsatellite genotyping of the sperm extracted from queen spermatheca proved to be a valuable method for estimating the frequency of multiple mating by

Table 3 Mating frequency of queens with alternative dispersal strategies, as detected by sperm analysis. Proportions are given in parentheses

\begin{tabular}{lllll}
\hline & \multicolumn{3}{l}{ Mating frequency } & \\
\cline { 2 - 4 } & 1 & 2 & 3 & Total \\
\hline Nondispersing queens & $75(0.78)$ & $17(0.18)$ & $4(0.04)$ & 96 \\
Dispersing queens & $46(0.78)$ & $12(0.20)$ & $1(0.02)$ & 59 \\
\hline
\end{tabular}


queens in the ant Formica paralugubris. The method is quick, powerful and cost effective, so that large numbers of queens can be analysed. A major advantage of this method is that it avoids the laborious analysis of large numbers of offspring reared in artificial single-queen colonies. Sperm typing will also be most useful for polygynous species which are difficult to rear under laboratory conditions (Queller 1993a; Goodnight et al. 1996).

The sperm-typing method is most useful in detecting single- vs. double-mating. Therefore, it might be applied to many social Hymenoptera, as queens of most species studied so far mate singly or with one or two males (Boomsma \& Ratnieks 1996). However, sperm typing will be less useful in species where the queens commonly mate with three or more males, such as bees of the genus Apis (Estoup et al. 1994; Moritz et al. 1995; Oldroyd et al. 1995, 1996, 1997), Vespula wasps (Ross 1986; Ross \& Carpenter 1991), and Atta ants (Gertsch \& Fjerdingstdad 1997; Fjerdingstad et al. 1998). Another limitation of the sperm-typing method is that it does not allow determination of the relative contributions of each mate. In the future, a quantitative approach (e.g. Ferré et al. 1994) might overcome this limitation.

Potential bias due to the contamination of the sperm sample with queen DNA can be accurately detected and corrected, provided that several loci with moderate to high heterozygosity are used. Similarly, nondetection of multiple males sharing identical genotypes will be negligible under most circumstances. A more serious bias, which affects both mother-offspring combinations and sperm-typing methods, is that rare patrilines might escape detection. In mother-offspring combinations, the number of offspring analysed is limited, which results in a nonsampling error (Pamilo 1982, 1993; Pedersen 1997). Similarly, the rarest male haplotype might not be amplified in PCR, which is an exponential, competitive process. The sensitivity limit for the accurate detection of a second mate by sperm typing is likely to vary among loci, and to depend on details of the experimental protocol. With the loci and methods used in this study, the second male was detected as long as it contributed more than $10 \%$ of the sperm stored by the queen. Such a sensitivity limit will be acceptable for many applications, because a second male fathering a small fraction of the brood has only a minor impact on the colony genetic structure. Finally, whatever the biases, sperm-typing data can be used in a comparative manner. For example, sperm-based estimates of the mating frequency of queens from the same population are probably biased in an uniform way. Hence, relative differences in mating frequencies of queens from the same population should translate into relative differences in the number of mates detected in the sperm they stored.

No difference in queen mating frequency was detected between $F$. paralugubris queens with alternative dispersal strategies. In particular, dispersing queens that might found new colonies did not mate with more males than queens staying within polygynous nests, where the presence of numerous queens already ensured high genetic diversity and production of diploid individuals. This suggests that the hypothetical benefits of multiple mating are smaller than the costs for dispersing $F$. paralugubris queens. These queens did not attempt to get a larger supply of sperm (Cole 1983), nor to bet-hedge against sterility of the first mate (Walker 1980), nor to select for more competitive sperm (Keller \& Reeve 1995), nor to increase genetic variability among their offspring (Crozier \& Page 1985; Keller \& Reeve 1994). Overall, this result provides no support to the idea that polyandry is favoured in monogynous species, as compared to polygynous ones (Keller \& Reeve 1994). Indeed, polyandry might be costly in species where queens found new colonies independently or through temporary social parasitism, because multiple mating increases the probability that a fraction of diploid brood will develop into sterile males, which might severely affect the survival of incipient colonies (Pamilo et al. 1994). The fact that most of the dispersing queens of $F$. paralugubris mated with only one male is in agreement with this load hypothesis. Empirical data from monogynous fire ants indicate that incipient colonies producing diploid males suffer from a high mortality (Ross \& Fletcher 1986). Interestingly, fire ant queens mate with a single male in both monogynous and polygynous populations (Ross \& Fletcher 1985; Ross 1993), which bears a close resemblance to the results of the present study. In agreement with the load hypothesis, no diploid male was found in some monogynous species of Formica ants, in contrast to polygynous ones (Pamilo et al. 1994). However, nests of other monogynous or weakly polygynous species produced diploid males (Pamilo et al. 1994). More data are needed to evaluate the effective role played by the load of diploid males in mating frequency selection.

Whatever their dispersal strategy, most queens of F. paralugubris mated with one male. Double and triple matings were detected for 19\% and 3\% of the queens, respectively. Overall, multiple mating had little effect on colony genetic structure: the effective mating frequency was only 1.11 when measured from within-brood relatedness, or 1.13 when estimated from the detected number of mates, assuming equal contribution of each male. Hence, the occurrence of a moderate proportion of multiple mating in F. paralugubris may not require an adaptive explanation. Multiple mating may occasionally arise from failures and errors during the mating process. For example, males may sometimes fail to transfer enough sperm, or queens may make errors in assessing their effective mating status. Alternatively, multiple mating may also result from male coercion, if it is more costly for queens to resist males than 
to suffer an additional mating (Clutton-Brock \& Parker 1995). Indeed, aggregations of males surrounding a single Formica female have frequently been observed during mating on open meadows (Cherix et al. 1991; M. Chapuisat, personal observation), and queens may also have difficulty in escaping male advances within the confines of the nest.

Overall, this study shows that F. paralugubris queens having very different life histories mate mostly with one male. This result might reflect a general trend among social Hymenoptera, where effective mating frequencies close to one are the rule (Boomsma \& Ratnieks 1996). For example, the average effective mating frequency across 19 ant species was below 1.16 (Boomsma \& Ratnieks 1996), a value close to the one obtained in the present study.

\section{Acknowledgements}

I thank William Brown, Laurent Keller and Francis Ratnieks for comments on the manuscript, Georgina Bernasconi for discussion on statistics, and Catherine Roger for laboratory assistance. This study was partially funded by the Swiss National Science Foundation and the Société Académíque Vaudoise.

\section{References}

Avise JC (1994) Molecular Markers, Natural History and Evolution, Chapman and Hall, NY.

Boomsma JJ, Ratnieks FLW (1996) Paternity in eusocial Hymenoptera. Philosophical Transactions of the Royal Society of London, Series B, 351, 947-975.

Bourke AFG, Franks NR (1995) Social Evolution in Ants, Princeton University Press, Princeton, NJ.

Chapuisat M (1996) Characterization of microsatellite loci in Formica lugubris $B$ and their variability in other ant species. Molecular Ecology, 5, 599-601.

Chapuisat M (1997) Social Evolution and Genetic Organization of Formica Ants. PhD thesis, University of Lausanne, Lausanne, Switzerland.

Chapuisat M, Goudet J, Keller L (1997) Microsatellites reveal high population viscosity and limited dispersal in the ant Formica paralugubris. Evolution, 51, 475-482.

Cherix D, Chautems D, Fletcher DJC et al. (1991) Alternative reproductive strategies in Formica lugubris Zett. (Hymenoptera Formicidae). Ethology Ecology and Evolution, Special Issue, 1, 61-66.

Cherix D, Fletcher DJC, Chautems D et al. (1993) Attraction of the sexes in Formica lugubris Zett. (Hymenoptera: Formicidae). Insectes Sociaux, 40, 319-324.

Clutton-Brock TH, Parker GA (1995) Sexual coercion in animal societies. Animal Behaviour, 49, 1345-1365.

Cohen J (1988) Statistical Power Analysis for the Behavioral Sciences, Lawrence Erlbaum, Hillsdale, NJ.

Cole BJ (1983) Multiple mating and the evolution of social behavior in the Hymenoptera. Behavioral Ecology and Sociobiology, 12, 191-201.

Crozier RH, Page RE (1985) On being the right size: male contributions and multiple mating in social Hymenoptera. Behavioral Ecology and Sociobiology, 18, 105-115.
Crozier RH, Pamilo P (1996) Evolution of Social Insect Colonies: Sex Allocation and Kin Selection, Oxford University Press, Oxford, UK.

Estoup A, Solignac M, Cornuet JM (1994) Precise assessment of the number of patrilines and of genetic relatedness in honey bee colonies. Proceedings of the Royal Society of London, Series B, $258,1-7$.

Evans J (1993) Parentage analyses in ant colonies using simple sequence repeat loci. Molecular Ecology, 2, 393-397.

Ferré F, Marchese A, Pezzoli P et al. (1994) Quantitative PCR: and overview. In: The Polymerase Chain Reaction (eds Mullis KB, Ferré F, Gibbs RA), pp. 67-88. Birkäuser, Boston, MA.

Fjerdingstad EJ, Boomsma JJ, Thorén P (1998) Multiple paternity in the leafcutter ant Atta colombica - a microsatellite DNA study. Heredity, 80, 118-126.

Gertsch PJ, Fjerdingstdad EJ (1997) Biased amplification and the utility of spermatheca-PCR for mating frequency studies in Hymenoptera. Hereditas, 126, 183-186.

Goodnight KF, Strassmann JE, Klingler CJ, Queller DC (1996) Single mating and its implications for kinship structure in a multiple-queen wasp, Parachartergus colobopterus. Ethology Ecology and Evolution, 8, 191-198.

Gösswald K (1953) Uber Versuche zur Verwendung von Hilfsameisen zwecks Vermehrung der nützlichen Kleinen Roten Waldameise. Zeitschrifft für Angewandte Entomologie, 34, 1-44.

Gösswald K (1989) Die Waldameise. Band 1. Biologische Grundlagen, Ökologie und Verhalten, Aula-Verlag, Wiesbaden.

Gyllensten UB (1990) Haplotype analysis from single sperm or diploid cells. In: PCR Protocols. A Guide to Methods and Applications (eds Innis MA, Gelfand DH, Sninsky JJ, White TJ), pp. 300-306. Academic Press, NY.

Hamilton WD (1964a) The genetical evolution of social behaviour. I. Journal of Theoretical Biology, 7, 1-16.

Hamilton WD (1964b) The genetical evolution of social behaviour. II. Journal of Theoretical Biology, 7, 17-52.

Hamilton WD (1987) Kinship, recognition, disease, and intelligence: constraints of social evolution. In: Animal Societies: Theories and Facts (eds Ito Y, Brown JL, Kikkawa J), pp. 81-102. Japan Scientific Society Press, Tokyo.

Keller L, Reeve HK (1994) Genetic variability, queen number, and polyandry in social Hymenoptera. Evolution, 48, 694-704.

Keller L, Reeve HK (1995) Why do females mate with multiple males? The sexually selected sperm hypothesis. Advances in the Study of Behavior, 24, 291-315.

Kutter H (1977) Hymenoptera, Formicidae, Schweizerische Entomologische Gesellschaft, Zürich.

Moritz RFA (1985) The effects of multiple mating on the workerqueen conflict in Apis mellifera L. Behavioral Ecology and Sociobiology, 16, 375-377.

Moritz RFA, Kryger P, Koeniger G et al. (1995) High degree of polyandry in Apis dorsata queens detected by DNA microsatellite variability. Behavioral Ecology and Sociobiology, 37, 357-363.

Oldroyd BP, Smolenski AJ, Cornuet JM et al. (1995) Levels of polyandry and intracolonial genetic relationships in Apis florea. Behavioral Ecology and Sociobiology, 37, 329-335.

Oldroyd BP, Smolenski AJ, Cornuet JM et al. (1996) Levels of polyandry and intracolonial genetic relationships in Apis dorsata (Hymenoptera, Apidae). Annals of the Entomological Society of America, 89, 276-283.

Oldroyd BP, Clifton MJ, Wongsiri S et al. (1997) Polyandry in the genus Apis, particularly Apis andreniformis. Behavioral Ecology and Sociobiology, 40, 17-26. 
Page RE (1980) The evolution of multiple mating behavior by honey bee queens (Apis mellifera L.). Genetics, 96, 263-273.

Page RE (1986) Sperm utilization in social insects. Annual Review of Entomology, 31, 297-320.

Page RE, Metcalf RA (1982) Multiple mating, sperm utilization, and social evolution. American Naturalist, 119, 263-281.

Pamilo P (1982) Multiple mating in Formica ants. Hereditas, 97, 37-45.

Pamilo P (1991a) Evolution of colony characteristics in social insects. II. Number of reproductive individuals. American Naturalist, 138, 412-433.

Pamilo P (1991b) Evolution of the sterile caste. Journal of Theoretical Biology, 149, 75-95.

Pamilo P (1993) Polyandry and allele frequency differences between the sexes in the ant Formica aquilonia. Heredity, 70, 472-480.

Pamilo P, Chautems D, Cherix D (1992) Genetic differentiation of disjunct populations of the ants Formica aquilonia and Formica lugubris in Europe. Insectes Sociaux, 39, 15-29.

Pamilo P, Sundström L, Fortelius W, Rosengren R (1994) Diploid males and colony-level selection in Formica ants. Ethology Ecology and Evolution, 6, 221-235.

Pedersen JS (1997) Variation in Social and Genetic Structure in the Red Ant, Myrmica sulcinodis. PhD thesis, University of Aarhus, Aarhus, Denmark.

Peters JM, Queller DC, Strassmann JE, Solís CR (1995) Maternity assignment and queen replacement in a social wasp. Proceedings of the Royal Society of London, Series B, 260, 7-12.

Queller DC (1993a) Genetic relatedness and its components in polygynous colonies of social insects. In: Queen Number and Sociality in Insects (ed. Keller L), pp. 132-152. Oxford University Press, Oxford, UK.

Queller DC (1993b) Worker control of sex ratios and selection for extreme multiple mating by queens. American Naturalist, 142, 346-351.

Queller DC, Goodnight KF (1989) Estimating relatedness using genetic markers. Evolution, 242, 258-275.

Ratnieks FLW (1990) The evolution of polyandry by queens in social Hymenoptera: the significance of the timing of removal of diploid males. Behavioral Ecology and Sociobiology, 26, 343-348.

Ratnieks FLW, Boomsma JJ (1995) Facultative sex allocation by workers and the evolution of polyandry by queens in social Hymenoptera. American Naturalist, 145, 969-993.

Ross KG (1986) Kin selection and the problem of sperm utilization in social insects. Nature, 323, 798-800.

Ross KG (1993) The breeding system of the fire ant Solenopsis invicta: effects on colony genetic structure. American Naturalist, 141, 554-576.
Ross KG, Fletcher DJC (1985) Comparative study of genetic and social structure in two forms of the fire ant, Solenopsis invicta (Hymenoptera: Formicidae). Behavioral Ecology and Sociobiology, 17, 349-356.

Ross KG, Fletcher DJC (1986) Diploid male production: a significant colony mortality factor in the fire ant, Solenopsis invicta. Behavioral Ecology and Sociobiology, 19, 283-291.

Ross KG, Carpenter JM (1991) Population genetic structure, relatedness, and breeding systems. In: The Social Biology of Wasps (eds Ross KG, Matthews RW), pp. 451-479. Cornell University Press, Ithaca, NY.

Sambrook J, Fritsch EF, Maniatis T (1989) Molecular Cloning: A Laboratory Manual, Cold Spring Harbor Laboratory Press, NY.

Schmid-Hempel P (1994) Infection and colony variability in social insects. Philosophical Transactions of the Royal Society of London, Series B, 346, 313-321.

Sherman PW, Seeley TD, Reeve HK (1988) Parasites, pathogens, and polyandry in social Hymenoptera. American Naturalist, 131, 602-610.

Shykoff JA, Schmid-Hempel P (1991a) Genetic relatedness and eusociality: parasite-mediated selection on the genetic composition of groups. Behavioral Ecology and Sociobiology, 28, 371-376.

Shykoff JA, Schmid-Hempel P (1991b) Parasites and the advantage of genetic variability within social insect colonies. Proceedings of the Royal Society of London, Series B, 243, 55-58.

Sokal RR, Rohlf FJ (1995) Biometry. The Principles and Practice of Statistics in Biological Research, Freeman, NY.

Starr CK (1984) Sperm competition, kinship, and sociality in the aculeate Hymenoptera. In: Sperm Competition and the Evolution of Animal Mating Systems (ed. Smith RL), pp. 428-464. Academic Press, London, UK.

Thornhill R, Alcock J (1983) The Evolution of Insect Mating Systems, Harvard University Press, Cambridge, MA.

Trivers RL, Hare H (1976) Haplodiploidy and the evolution of the social insects. Science, 191, 249-263.

Walker WF (1980) Sperm utilization strategies in nonsocial insects. American Naturalist, 115, 780-799.

This study was part of the PhD of Michel Chapuisat, which focused on intracolony conflicts, breeding systems and population genetics of Formica ants, as revealed by microsatellite markers. This work was carried out while the author held an assistant position at the Museum of Zoology in Lausanne, Switzerland. The molecular analyses were performed in the laboratory of the Institute of Zoology and Animal Ecology of the University of Lausanne. 